\title{
Bamboo Trusses with Low Cost and High Ductility Joints
}

\author{
Mauro Sassu, Marco Andreini, Anna De Falco, Linda Giresini \\ Department of Energy, Systems, Territory and Constructions Engineering, University of Pisa, Pisa, Italy \\ Email: m.sassu@unipi.it
}

Received August 5, 2012; revised September 10, 2012; accepted September 21, 2012

\begin{abstract}
Innovative solutions of joints for bamboo trusses are presented. Experimental tests show the performances and the high level of ductility of the proposed technique, joined with simplicity in the concept of the joints, low level of technology and low cost of all used materials. It can permit a proper dissemination and a sustainable maintenance in developing countries.
\end{abstract}

Keywords: Bamboo Constructions; Trusses; Structural Optimization; Low-Cost Technology

\section{Introduction}

The theme of the structural behaviour on traditional constructions is wide and complex. The necessity to get houses, schools and social or other public constructions with low-cost, simple to build and to maintain involves primary attention to communities. About 30\% of the world population lives in earth housing and about $50 \%$ of the earth houses are located in developing countries. In turn, the areas affected by the earthquake risk involve the majority of areas with low socio-economic development: large parts of Asia, Latin America and the Rift Valley in Africa are areas susceptible to earthquake or other extreme loads (i.e. tornados, heavy rains) [1-3].

It is well-known that low-cost new buildings should integrate with the habits of communities for availability of materials technical maintenance. Past experiences have shown that a strict import of modern construction techniques leads to rapid deteriorations due to problems of sustainability of the work and maintenance techniques and management. The implementation of indigenous building materials and structural forms should be socially harmonized to perform a real improvements in the construction types [4-8].

Bamboo is a low-cost building material available in wide parts of the world: it is lightweight, durable, flexible, and easily cultivated and processed [9-13].

An interesting use of bamboo for low-cost buildings is the erection of light roofs well-connected to the walls, and the arrangement of frames entirely made by bamboo or with the help of other materials. The mechanical properties of bamboo are relevant in seismic areas: lower inertia involves minor seismic actions and a good connection to the top of the walls reduces the slenderness for the benefit of stability [14-16].
A priority in structural behavior under earthquake is the ductility: unfortunately bamboo shows a short plastic phase after elastic limits - mainly in case of tractionand the collapse is often associated to fragile longitudinal fractures. Another inconvenient in traditional building techniques is the reduced strength due to the joints between bamboo rods, in respect to the resistance of the element. Traditional techniques typically require the use of ropes or ties with buckles, or the mortgage by simple snap: it can obtain simple knots but not efficient from structural point of view. However, improving technology permits high resistance joints even in the mentioned kind of areas but the technological transfer into the economic flow of developing countries [15-18] is quite hard. Proposal to optimize those aspects are presented.

\section{Optimization of Bamboo Connections}

A set of experimental studies and technical solutions for joints have been conducted to combine economy and ease with static and seismic saving. It has been proposed three different solutions of connections: each type of joint has been tested with traction experiments, applying quasi static loads, monotonic or cyclic, to reach the collapse of the element.

\subsection{Joint with Screw Nails and Steel Plate}

A first pilot proposal has been conducted in the laboratory of University of Pisa [19,20], with a single joint in a bamboo rod (diameter of $60 \mathrm{~mm}$, thickness of $5 \mathrm{~mm}$ ) reinforced with a massive wood cylinder, glued and/or screwed with a metal plate. The pilot trials showed the axial force displacement diagram in Figure 1, with three different stages of the mechanical behaviour: 


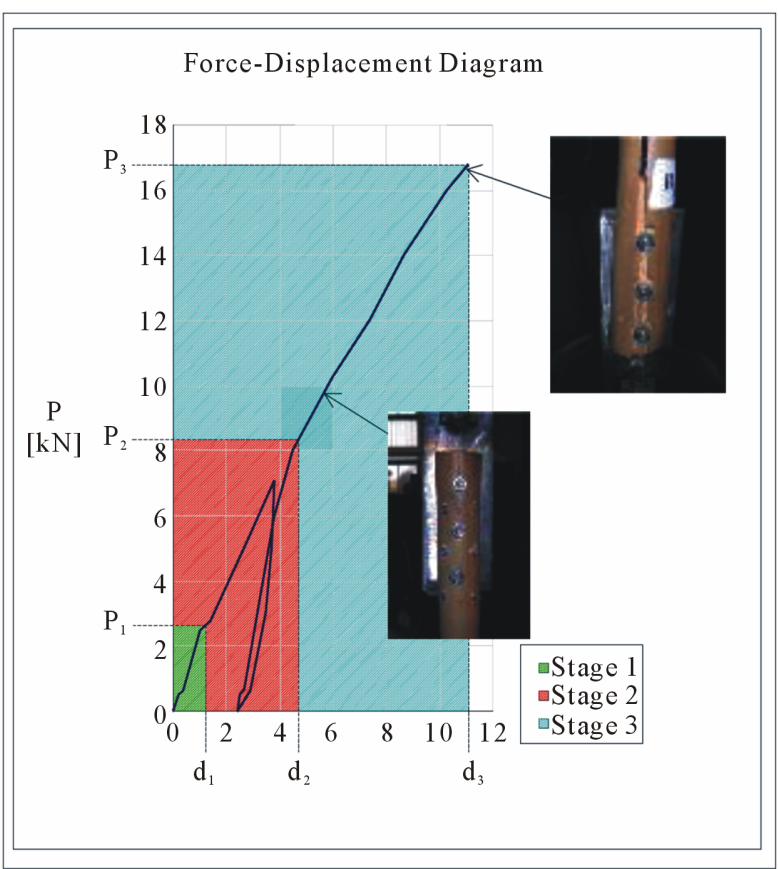

Figure 1. Traction test on 1st type joint.

Stage 1 (elastic): the connection highlights no cracking and the metal bolts and the glue layer are perfectly embedded in the wood mass.

Stage 2 (inelastic): the bamboo rod end reinforced by screw nails (joint $B$ ) reveals longitudinal splitting along the line of the hole centres; no movements are between the reinforcing wood cylinders and bamboo rod.

Stage 3 (collapse): the reinforced extremity (joint B) featured an increase of the longitudinal crack, without significant displacements between the wood core and the bamboo. Instead, the collapse was reached at the joint A, due to the slip between glued wood and internal vegetal skin, without significant plastic phase.

\subsection{Joint with Screw Nails and Plywood Plate}

An evolution of the joint to reach simpler solution and major ductility has been performed by way of plywood plates-instead of steel—and filling in the internal part of bamboo with a set of wooden sticks. In the Laboratory of the Polytechnic of Malawi [18,21] a series of nodes with single or twin connection, reinforced with slivers of bamboo and wooden plates screwed to the plywood has been tested. Two kinds of tests have been carried on. The first consists of a single rod traction test performed with two plywood plates bolt at the bottom, linked to the testing machine through two steel supports. The second type of joint connects a couple of bamboo rods through plywood plate and steel nails with a relative angle of about $60^{\circ}$. Both joints are fixed to the traction machine through appropriate steel supports as shown in Figure 2. The bamboo rods and plywood plate were linked by three steel bolts of $\varnothing 8 \mathrm{~mm}$; moreover a pine timber cylinder was inserted in the bottom of each of the rods to reinforce the link. This element is different in each pole. With the purpose to fix it to the bamboo and to improve the resistance of the joint, six screw nails of $\varnothing 4 \mathrm{~mm}$ and length of $40 \mathrm{~mm}$ were inserted to the bamboo joints.

The assembly of the specimen, simple and easy to disseminate, was carried out as follows:

- the internal reinforcements were modeled and inserted inside the bamboo rod;

- the bottom of the pole was cut in a longitudinal way to allow inserting the plywood plate;

- the bamboo rods were drilled and bolts with screw nails through the plate.
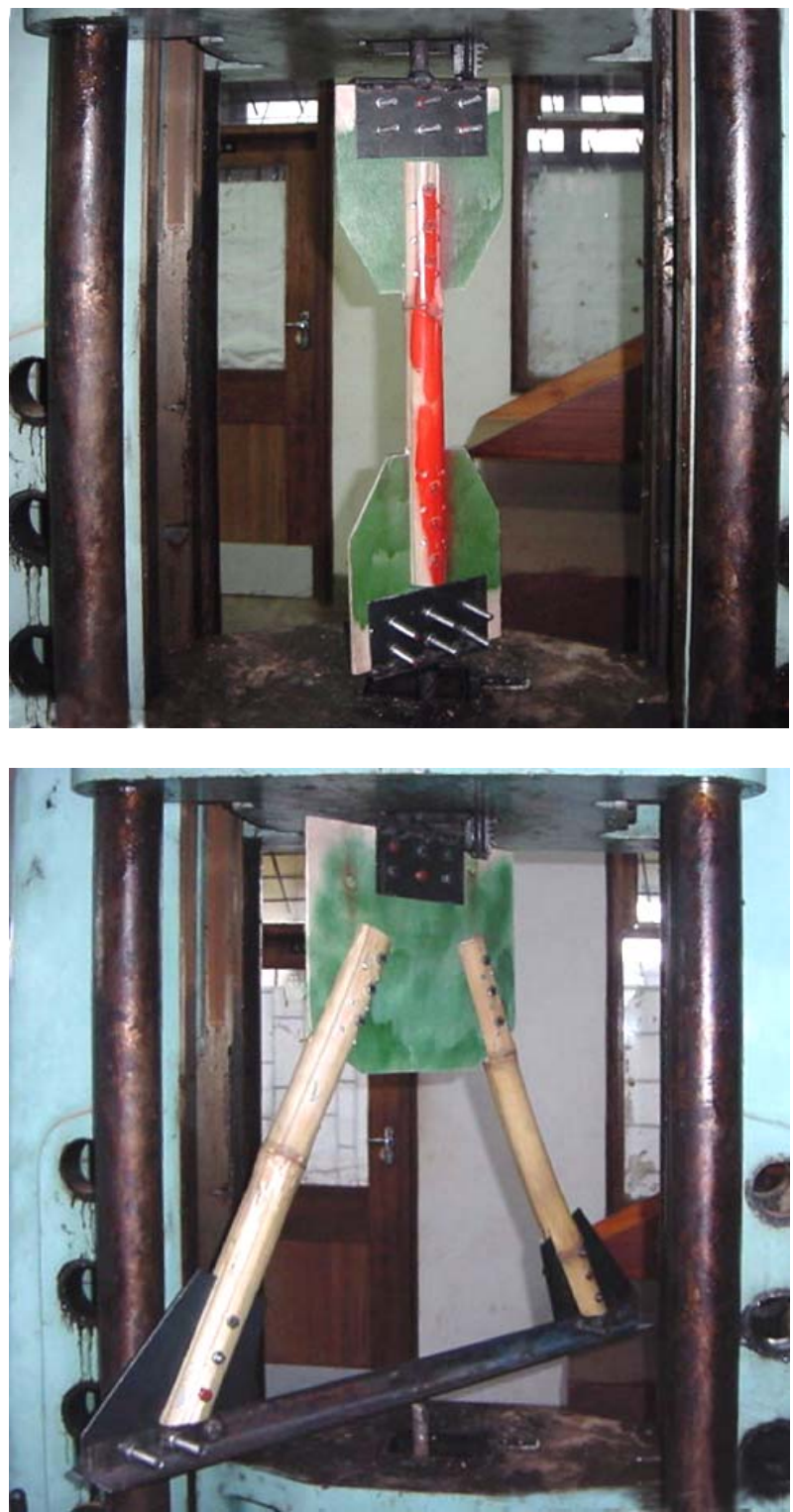

Figure 2. Tests on single and double 2nd type joints. 
A steel support (a couple of $2 \mathrm{~mm}$ steel plates) hanged the plywood plate to transmit the forces from the pole to the machine through the bolts and the friction between the two elements. The test machine is an Avery-Denison, with resolution of $50 \mathrm{daN}$ and a maximum load of 1000 $\mathrm{kN}$. The tests were performed in displacement control. The length of the rod were $470 \mathrm{~mm}$ in the single joint tests and $600 \mathrm{~mm}$ in the double joint tests; the average transverse section had a diameter of $50 \mathrm{~mm}$ and a thickness of $6 \mathrm{~mm}$. Table 1 summarize the experimental results of the collapse forces. The average ductility for single joint tests was 4.5 and for double joint tests 3.8: both remarkable values were due to the role of plywood strongly deformed around the bolts.

The main results of the tests have been the following:

- the use of plywood to connect bamboo elements through steel bolts permit ductility during collapse, due to the deformation of the holes around bolts;

- the joint reinforcement offered by timber cylinders inside the bamboo extremity avoids the fragility resulting from the longitudinal fracture of the bamboo fibers;

- in all tests the joint configuration permitted applying relevant normal stress on bamboo elements, giving the maximum high span of rods, useful for trusses especially for roofs, as in Figure 3;

- to avoid fragile collapse, nails or glue are applied for connecting the bamboo extremity to the internal wooden cylinder, or to execute external wraps for acting transverse containment.

\subsection{Joint with Wooden Pins and Plywood Plates}

The third proposed solution is the simplest from constructive and economic point of view: it consists of a

Table 1. Collapse force of traction tests.

\begin{tabular}{cccc}
\hline N. & Force [daN] & N. & Force [daN] \\
\hline 1 & 1380 & 1 & 450 \\
2 & 1380 & 2 & 400 \\
3 & 1300 & 3 & 550 \\
4 & 1300 & 4 & 800 \\
5 & 1400 & 5 & 840 \\
6 & 1400 & 6 & 850 \\
7 & 750 & & \\
8 & 750 & \multicolumn{2}{|}{ Single rod (up) } \\
9 & 970 & \multicolumn{2}{|}{ Coupled rod (left) } \\
10 & 970 & & \\
11 & 1100 & & \\
12 & 1100 & & \\
\hline
\end{tabular}

couple of bamboo rods connected by wooden pins, instead of steel nails, without the insertion of the wooden core and transversally reinforced by canapé ropes. The entire constructive process can be conducted by a portable drill to execute the holes on the bamboo and on the plywood plates, a hammer and a saw to fix and cut the wooden nails, using only low-technology structural materials (Figure 4).

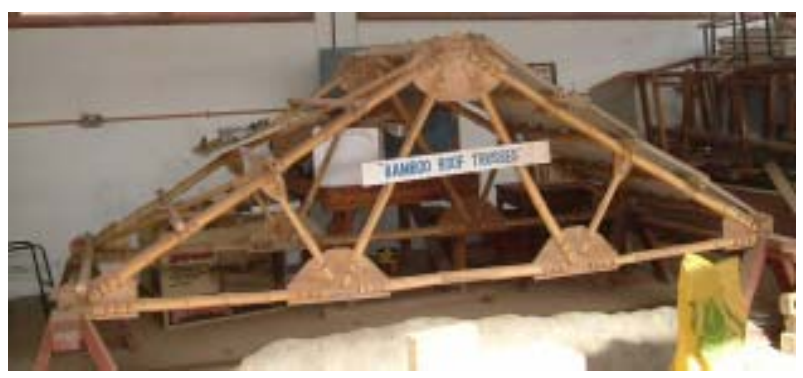

Figure 3. Truss with 2nd type joint.

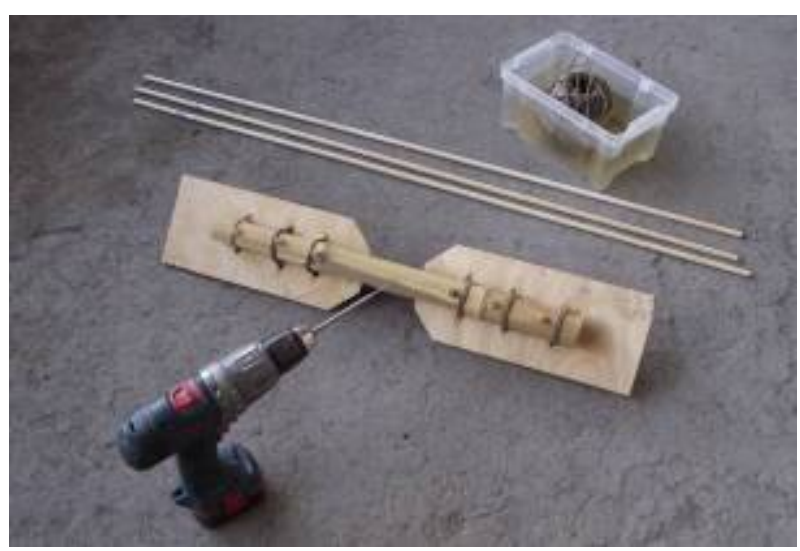

Figure 4. The 3rd type joint with drill and materials used.

Traction tests have been performed using specimen in Figures 5 and 6 (bamboo rod diameter of $50 \mathrm{~mm}$ and thickness of $5 \mathrm{~mm}$, plywood thickness of $8 \mathrm{~mm}$, canapé wire diameter of $3 \mathrm{~mm}$ ) with a couple of connecting steel element designed to avoid premature collapses on the hanging area. The canapé wires have been manually pre-stressed around the bamboo elements through holes in the plywood.

The tests, regarding three couples of joints, have been executed on INSTRON Mod. 1186 with full scale of $1000 \mathrm{daN}$, controlling relative displacement of upper and lower joint with n.4 LVDT transducers (precision 1/100 $\mathrm{mm}$ ) as in Figure 7. The main results are summarized in Table 2, while in Figure 8 is the typical diagram of traction force $F$ and relative displacement $d$ of each joint: the collapse traction tests have been conducted applying cycles with increasing loads. It is possible to individuate following four stages in the mechanical behavior of the connections: 

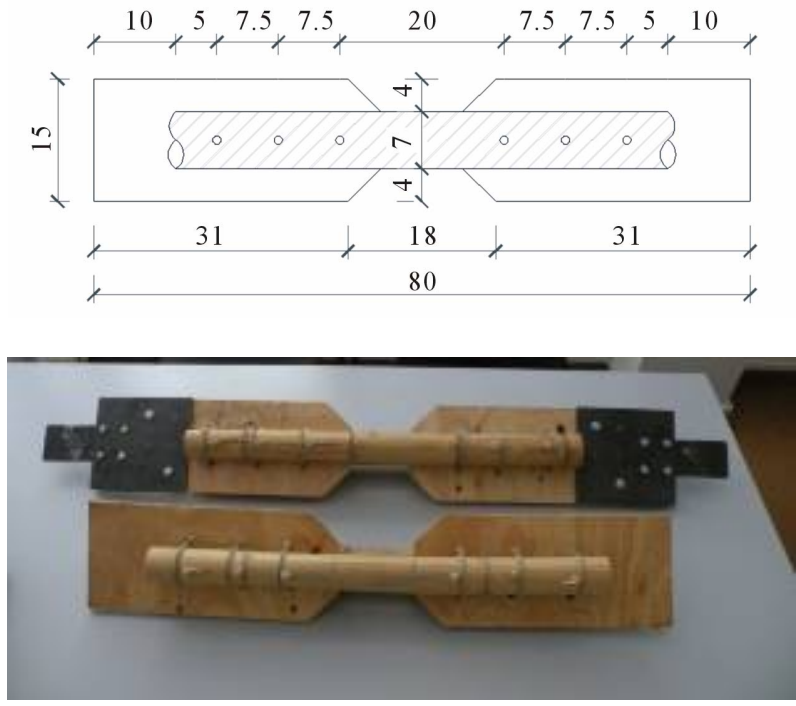

Figure 5. The specimen for traction tests on 3rd type joint.
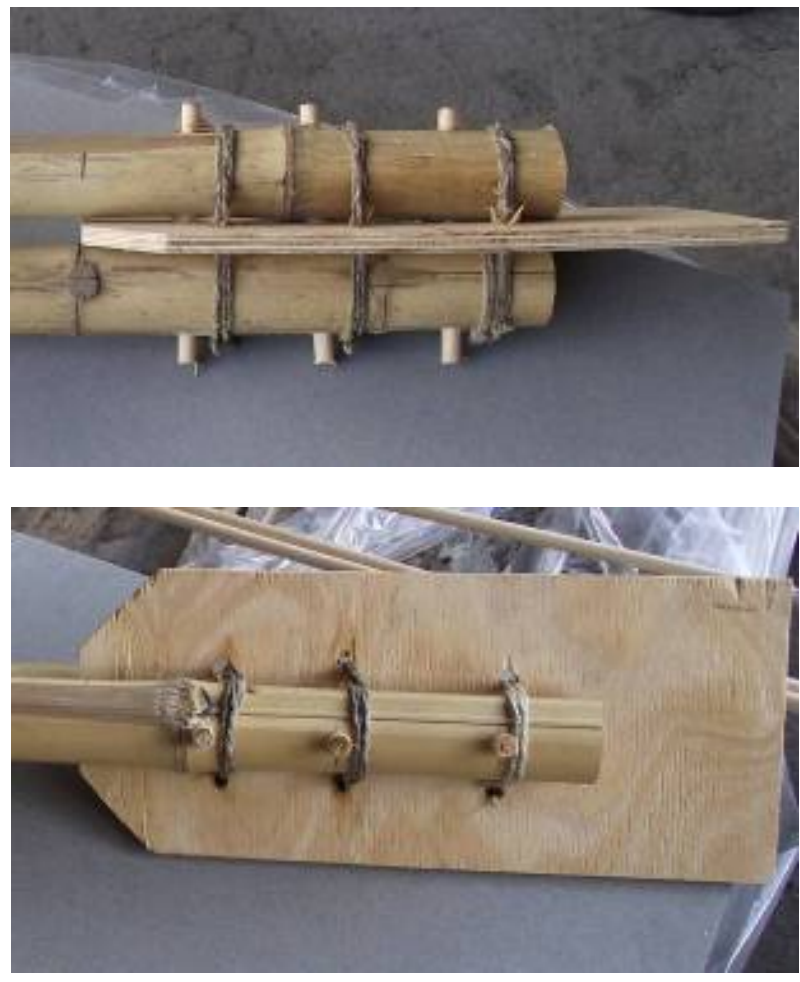

Figure 6. The assembled 3rd type joint.

1) The joint shows elastic characteristics, without relative displacements between plywood and bamboo;

2) Relative displacements between plywood and bamboo are due to the bending of wooden pins;

3) Inelastic large deformations in wooden pins perform wide relative displacements up to collapse.

4) Softening behavior are due to the progressive rupture of the wooden pins (starting from the extremity pins) partially constrained by the canapé.

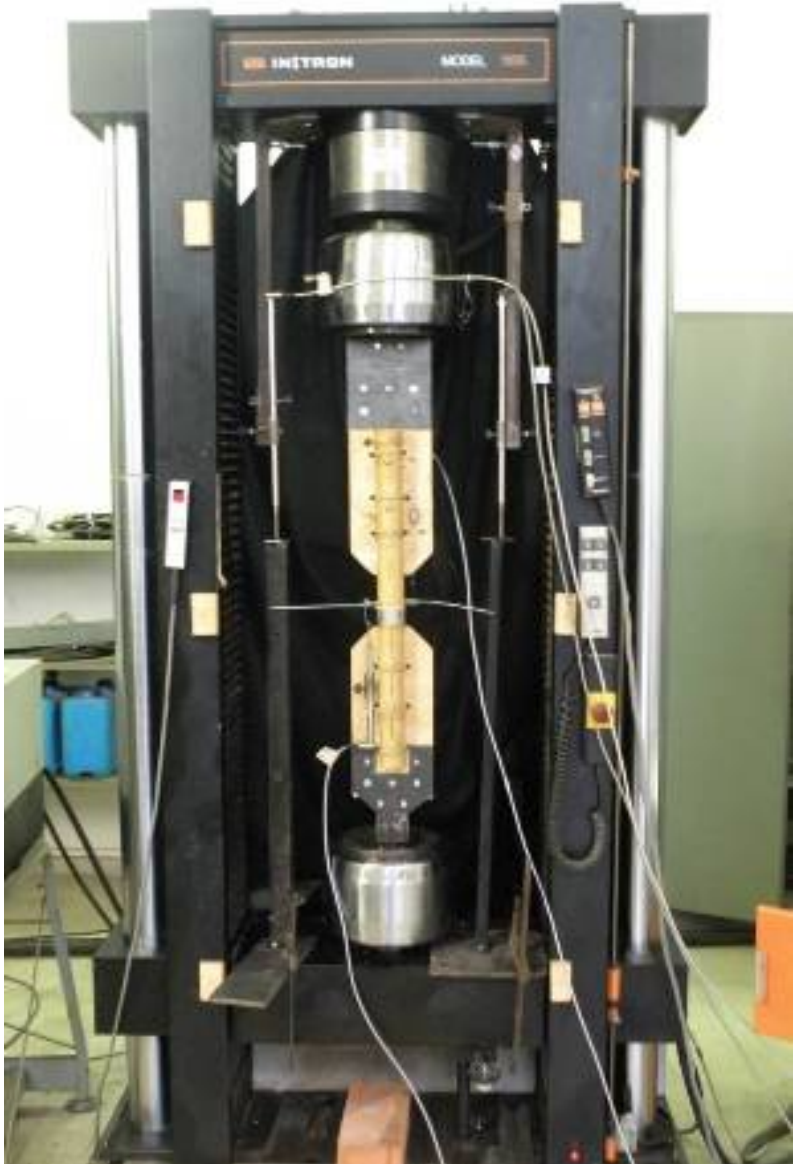

Figure 7. The traction tests on 3rd type joint.

Table 2. Force $P[\mathrm{kN}]$ - displacement $\mathbf{d}[\mathrm{mm}]$ of the tests.

\begin{tabular}{cccccccc}
\hline Spec. & Joint & $\boldsymbol{P}_{\mathbf{1}}$ & $\boldsymbol{d}_{\mathbf{1}}$ & $\boldsymbol{P}_{\mathbf{2}}$ & $\boldsymbol{d}_{\mathbf{2}}$ & $\boldsymbol{P}_{\mathbf{u}}$ & $\boldsymbol{d}_{\mathbf{u}}$ \\
\hline 1 & Top & 4.60 & 1.25 & 6.09 & 2.10 & - & - \\
1 & Down & 4.85 & 1.80 & 6.67 & 5.04 & 7.65 & 7.72 \\
2 & Top & 2.80 & 1.79 & 4.66 & 3.38 & 5.67 & 5.72 \\
2 & Down & 2.92 & 0.78 & 4.93 & 1.73 & - & - \\
3 & Top & 3.26 & 2.26 & 7.92 & 7.99 & 9.19 & 10.46 \\
3 & Down & 2.46 & 0.83 & 5.69 & 2.65 & - & - \\
\hline
\end{tabular}

The collapses of wooden pins (diameter of $10 \mathrm{~mm}$ ) protect plywood and bamboo elements from damages: the joint has been then repaired replacing the wooden bars and the canapé rods; the further tests provided similar results.

It is noted in Table 2 that the collapse load could be reached only in one of the two ends of the sample: nevertheless it has been possible to obtain, on both joints of each sample, the elastic limit value $P_{1}$ and the start of inelastic deformations in the wooden pins $P_{2}$.

It is noted in Table 2 that the ultimate value of the 


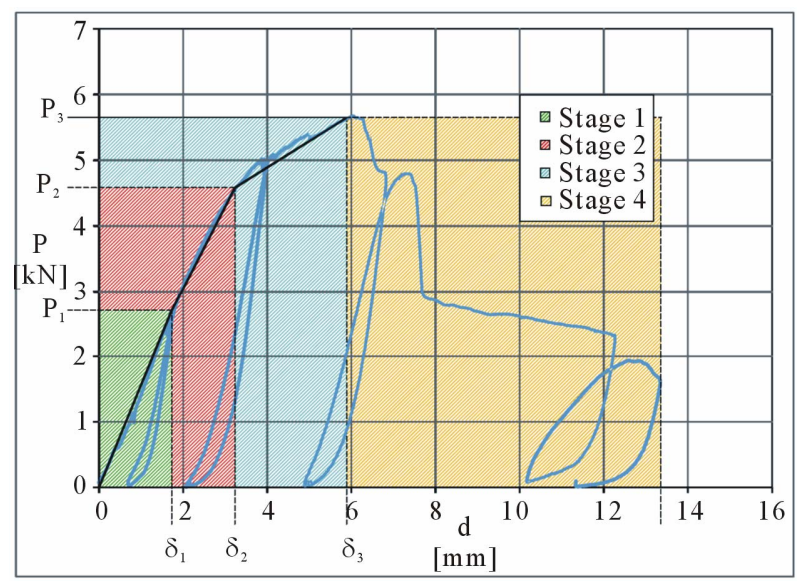

Figure 8. Typical Force $[\mathrm{kN}]$ —displacement [mm] diagram.

load could be reached in one of the two ends of the sample: nevertheless it has been possible to obtain, on both joints of each sample, the elastic limit value $P_{1}$ and the value of start of inelastic deformations in the wooden pins $P_{2}$. The main collapse mechanisms are:

1) Shear-bending rupture of wooden pins;

2) Upsetting of the holes in plywood plate;

3) Traction tearing of the bamboo cane;

4) Longitudinal crack on bamboo cane between the holes.

The design of joints has been addressed to conduct the mechanism n.1 ("weak pins") as in Figure 9.

This allowed ductility factor of node $\mu=d_{u} / d_{1}$ between 3.2 and 4.6, typical values of a ductile behavior, in spite of the fragility of the material bamboo without losing significantly in strength. Indeed, the classic formula of the design traction load of bamboo cane (ISO/DIS 22156) with net area $A$ and strength $f_{k}$ is:

$$
P_{d}=A f_{k} G D / \gamma_{m}
$$

where $G$ is a load factor (1.0 - 1.5), D reliability factor in execution (mainly 0.5$), \gamma_{m}$ safety factor of bamboo (2.25). In the present case from the current values of $A$ equal to $13.7 \mathrm{~cm}^{2}$ and $f_{k}$ of $18 \mathrm{MPa}$, it can be obtain

$$
P_{d}=5.50-8.25 \mathrm{kN}
$$

Comparable to $P_{1}$ in Table 2. This last type of joint allows a remarkable combination of static performance and ease technological and design, favoring the composition of the nodes of a truss. Using, for example, a Polanceau scheme is possible to reproduce the various nodes assembling only the tested joint on plywood plates of different geometry as in Figure 10.

An example of truss frame as shown in Figure 11, can be adopted for a series of one-floor constructions as housings, schools, social or medical centers.

\section{Conclusions}

The three proposed types of joints, furnishing different

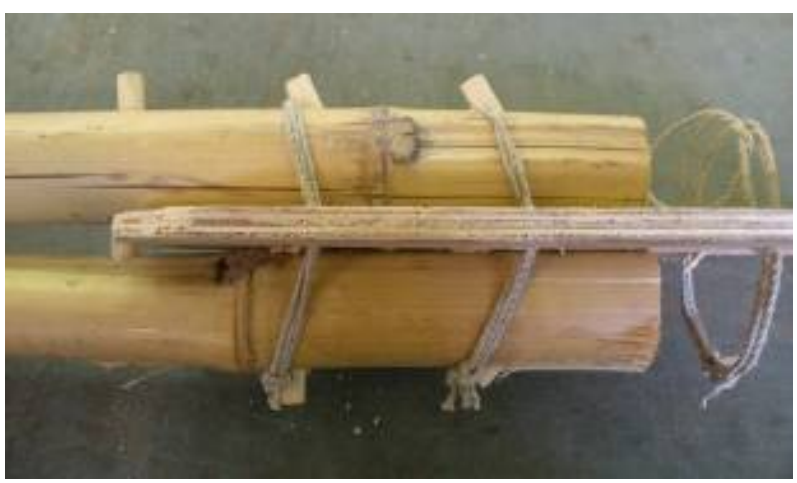

Figure 9. View of a collapsed joint.
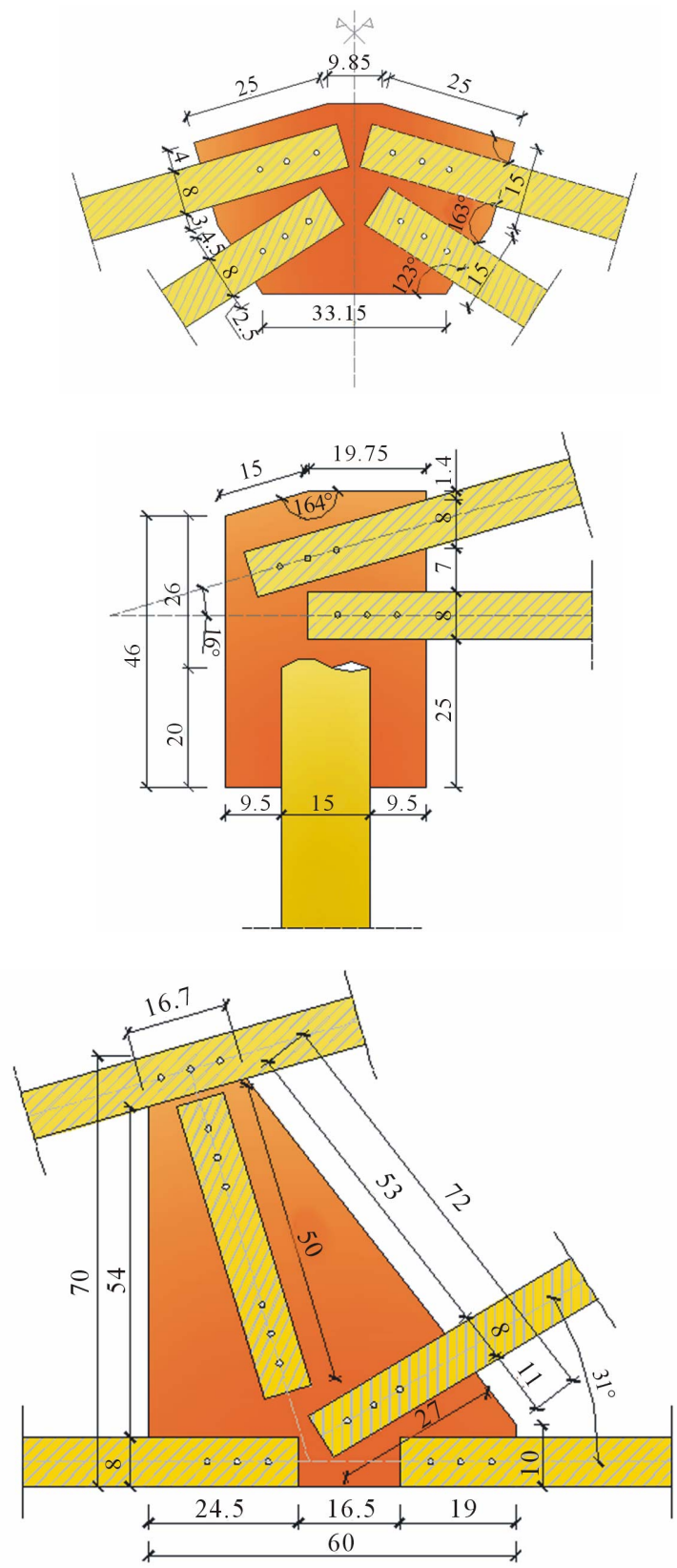

Figure 10. Nodes of polanceau truss with 3rd type joint. 


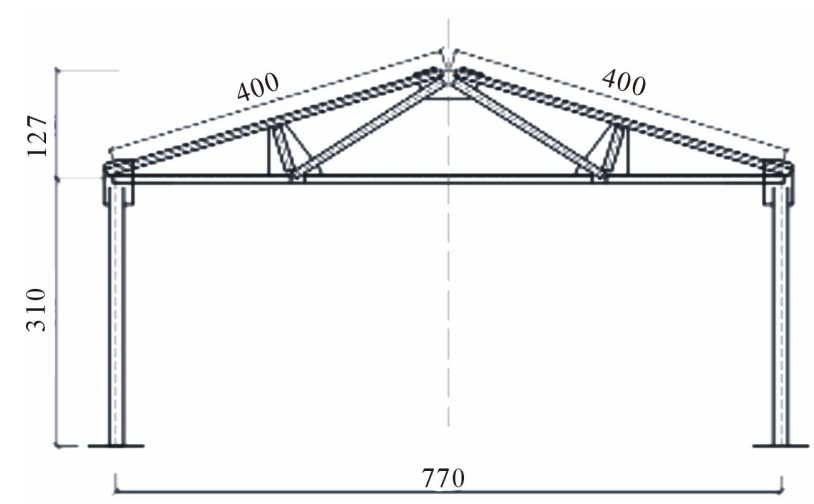

Figure 11. Truss frame for one-floor construction.

solutions in terms of technology: it can be seen an increasing ductility from the first to third joint, together with an improvement of simplicity executive and a lowering of the level of technology.

Moreover the strategy of "weak pins" allows quick and easy to repair of the nodes, avoiding collapses in the bamboo canes or in the plywood plates.

Finally the application of the joints to roof trusses permits the use of the same nodes for different size of the frame ensuring it a certain homotheticity: same nodes are useful for a range of trusses, giving an interesting degree of prefabrication to the structural system.

\section{REFERENCES}

[1] C. Comartin, S. Brzev, F. Naeim, M. Greene, M. Blondet, S. Cherry, D. D’Ayala, M. Farsi, S. Jain, J. Pantelic, L. Samant and M. Sassu, "A Challenge to Earthquake Engineering Professionals,” Earthquake Spectra, Vol. 20, No. 4, 2004, pp. 1049-1056. doi:10.1193/1.1809130

[2] P. Maydl, "Sustainable Engineering: State-of-the-Art and Prospects,” Structural Engineering International, Vol. 14, No. 3, 2004, pp. 176-180.

[3] J. O. Oyawa, "Eco-Materials for Developing Countries," Structural Engineering International, Vol. 14, No. 3, 2004, pp. 208-212.

[4] D. Romagno and M. Sassu, "Low Cost Seismic Constructions: Design and Dissemination in Developing SocioEconomic Areas,” Proceedings INTED09, Valencia, 9-11 March 2009, pp. 2808-2818.

[5] M. Sassu, “Chapter 7: Vernacular Construction," In: World Housing Encyclopedia, Oakland, 2004, pp. 1-10.

[6] H. Schreckenbach, "Training Strategies for an R \& D Project in Technical Co-Operation: Low-Cost Housing Technologies in Kenya,” Building Advisory Service and Information Network, No. 22, 2001.
[7] R. Stulz, “Appropriate Building Materials,” SKAT and Intermediate Technology Publications Ltd., CH-9000, St. Gallen, 1983.

[8] C. Sumerauer, "Connecting Bamboo Know-How Resources Globally for Sharing Knowledge,” Building Advisory Service and Information Network, No. 25, 2003.

[9] S. K. Paudel, "Proceeding of Bamboo Housing Workshop,” INBAR Proceeding No. 10, 2003. http://www.inbar.int/InfoPortal.htm

[10] J. A. Janssen, “Mechanical Properties of Bamboo,” Eindhoven University of Technology, Kluwer Academic Publishers, The Netherlands, 1991. doi:10.1007/978-94-011-3236-7

[11] J. A. Janssen, "Building with Bamboo: A Handbook," Intermediate Technology Publications Limited, London, 2000.

[12] D. L. Jayanetti and P. R. Follet, "Bamboo in Construction, an Introduction,” TRADA Technology Ltd., Biclinghamshire, 1998.

[13] P. R. Follet, "Earthquake-Proof House Shakes Bamboo World," Proceedings of the Institution of Civil Engineers, Vol. 157, No. 3, 2004, p. 102.

[14] H. N. Mishra and S. N. Sanyal, "Mature Bamboo in Mass Housing," Proceeding of the 4th International Workshop, Chiangmai, 27-30 November 1991, pp. 309-314.

[15] A. Kumar, I. V. Ramanuja Rao and C. B. Sastry, "Bamboo for Sustainable Development: Proceedings of the 5th International Bamboo Congress,” INBAR Proceeding No. 7, 1998.

[16] O. A. Arce, "Connection of Bamboo Elements. Bamboo in Asia and the Pacific," Proceeding of the 4th International Workshop, Chaingmai, 27-30 November 1991.

[17] P. Taylor and M. B. Luther, "Evaluating Rammed Earth Walls: A Case Study,” Solar Energy, Vol. 76, No. 1-3, 2004, pp. 79-84. doi:10.1016/j.solener.2003.08.026

[18] M. Sassu, D. Romagno, I. Ngoma, N. Puccinelli and R. Bonicoli, "A Proposal for Low-Cost Earthquake-Resistant Bamboo Buildings,” TEP Editor, Pisa, 2010

[19] M. Froli, G. Mariani, I. Ngoma and M. Sassu, “A Pilot Test on the Problem of Joining Steel Plates to Bamboo Rods," Proceedings of Department of Structural Engineering-University of Pisa, Vol. 1, 2003, p. 14.

[20] I. Ngoma and M. Sassu, "Sustainable African Housing through Traditional Techniques and Materials: A Proposal for a Light Seismic Roof,” 13th World Conference on Earthquake Engineering, Vancouver, 1-6 August 2004, Paper No. 170.

[21] M. Sassu, M. Andreini and I. Ngoma, “A Proposal of Bamboo Frameworks for Low-Cost Constructions in Seismic Areas,” SEMC 2010, Cape Town, Vol. 1, 2010, pp. 235-242. 